\title{
ОЦЕНКА КОНКУРЕНТОСПОСОБНОСТИ УСЛУГ СУБЪЕКТОВ ТУРИСТИЧЕСКОГО ПРЕДПРИНИМАТЕЛЬСТВА В СЕЛЬСКОЙ МЕСТНОСТИ (ПО ЭЛЕМЕНТУ «КАЧЕСТВО»)
}

\begin{abstract}
В статье проведено исследование существующих подходов к сущности конкурентоспособности предприятия, концепции управления качеством туристических услуг в сельском туризме, предложена авторская позиция к формированию системы управления конкурентоспособностью субъектов туристического предпринимательства в сельской местности по элементу «качество предоставления услуг. Авторы обосновали, что сущность управления качеством туристических услуг в сельском туризме состоит в формировании управленческих решений и реализации предусмотренных этими решениями управленческих действий относительно бизнес-процессов, от которых зависит качество услуг, а именно: документально оформленные инструкции относительно технологии предоставления услуг и обслуживания, регулирование и управление процессами предоставления туристических услуг, критерии выполнения работ, представленные в виде стандартов, использование новейших информационных технологий во время производства, реализации и продвижение туристической услуги на рынок.

Для оценки качества предоставления услуг субъектами предпринимательства в сельской местности были применены метод Дельфи, который является неформализованным методом системного анализа качества и построение петли качества. Также, в статье изложены результаты проведенных исследований относительно оценки качества предоставления туристических услуг субъектами предпринимательства в различных областях Украины и построен радар их конкурентоспособности (на основе проведенных исследований относительно оценки качества предоставления туристических услуг субъектами предпринимательства в Закарпатской, Волынской, Полтавский, Харьковских областях и Автономной Республике). Также, дополнены принципы управления качеством с учетом отраслевой специфики туристической деятельности в сельской местности, среди которых необходимо выделить обеспечение качества туристических услуг на всех уровнях
\end{abstract}

1 Lesia Zaburanna, Professor, doktor habilitowany, Professor of Management department of National University of Life and Environmental Sciences of Ukraine, Basseyna str., 15, Apt. 31 Kyiv, Ukraine, 01004, corresponding author: alesenka2003@ukr.net

2 Irina Evtyukova, Applicant NSC "Institute of Agricultural Economics", Scientific adviser: prof. Lesya Zaburanna, Geroev Oborony str., 10, of. 221 Kyiv, Ukraine, 03680 
управления во всех задействованных в этом процессе субъектах туристической деятельности, налаживание таких взаимодействий, при которых каждый сотрудник способен решать проблемы качества туристических услуг на своем рабочем месте, управление качеством туристических услуг на основе собранной информации относительно изменений в нуждах клиентов, стратегии и тактики конкурентов, а также в своих ресурсах, технологических возможностях и мощностях.

Ключевые слова: сельский туризм, конкурентоспособность предприятия, качество туристических услуг, петля качества, радар конкурентоспособности, принципы управления качеством туристических услуг.

\section{1. АКТУАЛЬНОСТЬ ИССЛЕДОВАНИЯ}

Процессы, происходящие в настоящее время в аграрном секторе экономики Украины, предопределяют поиск новых нетрадиционных организационно правовых форм предпринимательства, направленных на обеспечение экономического роста. Одним из приоритетных путей преодоления кризиса, который сложился в аграрном секторе, является активизация сельского населения к предпринимательской деятельности в непроизводственной сфере сельского туризма.

В Украине при оценке деятельности субъектов туристического предпринимательства в сельской местности почти не используются разные инновационные подходы к оценке их конкурентоспособности и ее составных, прежде всего качества услуг. Область сельского зеленого туризма представлена, как правило, малыми, семейными предприятиями, которые часто не могут осуществлять деятельность по продвижению своего продукта на рынок, оценивать деятельность своего предприятия с точки зрения его конкурентных преимуществ в области повышения качества предоставления услуг и т.п.

Поэтому возникает необходимость определения оценочных показателей качества услуг субъектов туристического предпринимательства в сельской местности как составной конкурентоспособности.

\section{2. АНАЛИЗ ПОСЛЕДНИХ ИССЛЕДОВАНИЙ И ПУБЛИКАЦИЙ}

Различными аспектами теории конкуренции и конкурентного поведения предприятий отводилось внимание в роботах таких зарубежных специалистов, как Ансофф И., Карлофф Б., Кинг Р., Портер М., Томпсон А. А., Стрикланд А. Дж. и др. Проблемы конкурентоспособности приобрели широкое развитие в роботах многих ученых, а именно: Г. Азоева, О. Градова, Н. Герасимчкук, В. Марченко, Т. Мостенской, О. Гудзинского, Л. Смоловар, Р. Фатхутдинова, А. Юданова и др. Общие вопросы, связанные с функционированием индустрии туризма, в т.ч. сельского, исследовались Браймером Р., Джанджугазовой Е.А, Луцкой Т. В., Маліком М. И., Уокером Дж. и др. Освещением вопросов создания комплексной гостиничной услуги, как отдельного вида туристического продукта, способного удовлетворять потребности потребителя занимались такие научные работники, как А. Дурович, Т.Агафонова, М. Босовская, М. Кабушкин, П. Лоуренс, Дж. Лорш, М. Портер, Т.Ткаченко, Х. Роглев, Л. Ходорков, Л. Шульгіна. 
Однако, несмотря на довольно большое количество научных работ по этой проблеме, теоретические вопросы оценки качества предоставления услуг субъектами туристического предпринимательства в сельской местности, как составляющей их конкурентоспособности недостаточно исследованы и остаются постоянным объектом дискуссий. Результаты существующих исследований не всегда успешно реализуются в практической деятельности этих предприятий.

Необходимость дальнейшего усовершенствования теоретических и методикоприкладных подходов относительно оценки конкурентоспособности услуг за элементом «качество», которые предоставляют субъекты туристического предпринимательства в сельской местности, обусловило актуальность исследования.

\section{3. ОСНОВНАЯ ИДЕЯ}

Ученый Половинка Ю.С. отмечает, что «главный критерий конкурентоспособности, от которого зависят конкурентные позиции производителя соответствующего товара или услуги», это - «возможность предоставлять покупателю преимущества по основным параметрам товара или услуги, которые предлагаются на рынок» ${ }^{3}$ Романова В. В. предлагает «причины конкурентоспособности искать в конкурентных преимуществах отдельных характеристик услуги или товара, что является следствием, прежде всего более эффективного управления процессом разработки, реализации и эксплуатации», а конкурентные преимущества она определяет, как «те характеристики и свойства, которые создают для фирмы определенное преимущество над своими прямыми конкурентами». «Концентрированное проявление результата более эффективной адаптации к условиям конкурентного среды за счет инновационного развития качественных и количественных характеристик процесса или продукта» называется «конкурентным преимуществом» 5 . «Конкурентные преимущества должны отвечать следующим критериям: представлять выгоды для потребителей, быть уникальными, быть стойкими» ${ }^{6}$ В таком случае, конкурентные преимущества субъектов туристического предпринимательства - это те уникальные и стойкие свойства туристического продукта, которые создают для него определенное преимущество над своими прямыми конкурентами. Причем, «чем шире в компании набор

${ }^{3}$ Ю. С. Половинка, Концепція управління якістю / Ю. С. Половинка, І. С. Грозний // Інтеграційні процеси і соціально-економічний розвиток : міжн. Науково-практ. Конфер., 2526 квітня, 2007 р. : тези конф. - Сімферополь : Таврія, 2007. - С. 233-235 - с.234.

4 В. В. Романова, Взаємозв'язок конкурентоспроможності і конкурентоспроможного потенціалу / В. В. Романова // Проблеми економіки. —2007. - № 1.- С. 283-285.

${ }^{5}$ Малевський Е. 3. Стратегія формування та досягнення конкурентних переваг промисловим підприємством / Е. 3. Малевський // Культура народов Причерноморья. - 2007. - №103. - С. 191-195 - с. 192.

6 Т. М. Алябышева, Теоретические и методические аспекты оценки конкурентных преимуществ региона / Т. М. Алябышева // Культура народов Причерноморья. - 2007. - № 102 - C. $55-58-$ c.56. 
конкурентных преимуществ, чем перспективнее предпосылки для ее успешной деятельности на рынке, тем более стойкие позиции она может занять в отдельных сегментах рынка» ${ }^{7}$. Одним из важнейших конкурентных преимуществ предприятия есть преимущество за счет качества продукции или услуги.

Для эффективного обеспечения конкурентоспособности услуг субъектов туристического предпринимательства в сельской местности также актуальной проблемой является оценка их качества. При этом ключевую роль имеет не только выявление внутренних причин, но и изучение нужд клиентов, а также образа удовлетворения данных нужд.

Субъекты туристического предпринимательства должны не только выявить внутренние факторы, влияющие на качество услуг, но и изучить весь комплекс запросов и нужд клиентов, создать и реализовать методику и технологию, которые обеспечат наиболее полное их удовлетворение. Эффективное управление качеством услуг, которые предоставляются, является важнейшим рычагом повышения уровня обслуживания клиентов, прибыльности бизнеса, обеспечение его экономической безопасности ${ }^{8}$.

Концепция качества многогранная и охватывает все свойства услуги, а именно: технические и другие характеристики, уровень предпродажной подготовки, сопровождение услуги в процессе ее предоставления, продвижение на рынке и обеспечение ее престижности в конкурентной среде.

Конкурентоспособность услуг субъектов туристического предпринимательства в сельской местности определяется уровнем их качества и цены. Качество комплексное понятие, которое всесторонне характеризует эффективность деятельности, стиль управления, стратегию, маркетинг и организацию предоставления услуг, поэтому эффективное управление качеством является одной из наиболее актуальных проблем ${ }^{9}$. Качество влияет на конечный результат (прибыль) и увеличивает объем предоставления услуг.

На наш взгляд, сущность управления качеством туристических услуг в сельском туризме состоит в формировании управленческих решений и реализации предусмотренных этими решениями управленческих действий относительно бизнес-процессов, от которых зависит качество услуг, а именно:

- документально оформленные инструкции относительно технологии редоставления услуг и обслуживания;

- регулирование и управление процессами предоставления туристических услуг;

\footnotetext{
${ }^{7}$ Е. Н. Унтила, Экологическая составляющая конкурентоспособности фирмы / Е. Н. Унтила // Культура народов Причерноморья. - 2001. - №21. - С. 50-51.

8 Л.Г. АГАФОНОВА, ТУРИЗМ, ГОТЕЛЬНИЙ та РЕСТОРАННИЙ БІЗНЕС/ Л.Г. АГАФОНОВА, О.Є. АгАФоновА. - К. : Знання України, 2002. - 352 с.; Глівенко С.В. Економічне прогнозування [Текст] : навч. Посібник / С. В. Глівенко, М. О. Соколов, О. М. Теліженко. - 3-є вид., доп. Суми : Університетська книга, 2004. - 207 с.

${ }^{9}$ Х.Й. Роглєв, Основи готельного менеджменту [Текст] : підруч. для студ. вищ. навч. закл. / Роглєв Х.Й. ; Київськ. ун-т туризму, екон. і права. - К. : Кондор, 2009. - 407 с.
} 
- критерии выполнения работ, представленные в виде стандартов;

- использование новейших информационных технологий во время производства, реализации и продвижение туристической услуги на рынок.

Рис.1. Система управления конкурентоспособностью субъектов туристического предпринимательства в сельской местности (по элементу «качество предоставления услуг»)

1. Исследование текущей ситуации относительно конкурентоспособности субъектов предпринимательской деятельности в сельской местности и качества предоставленных ими услуг

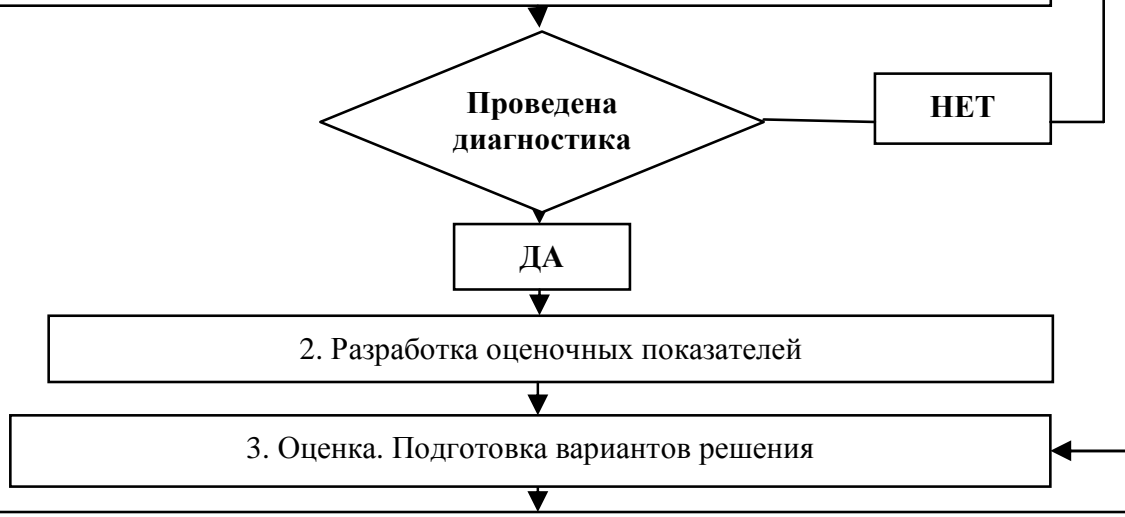

4. Оценка результативности и эффективности процесса после проведения оценки конкурентоспособности субъектов предпринимательской деятельности в сельской местности и повышения качества представленных ими услуг

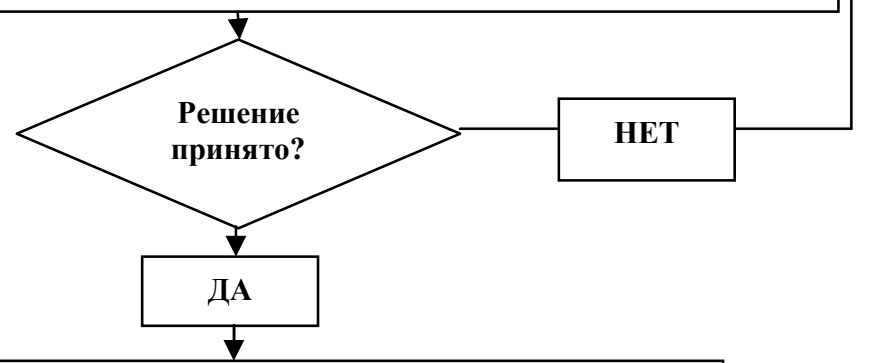

5. Принятие решения по повышению конкурентоспособности субъектов предпринимательской деятельности в сельской местности и качества предоставленных ими услуг 
Характеристики услуг туристического предпринимательства в сельской местности отображаются на процессе проектирования эффективной открытой системы управления качеством и влиянии данной системы на них конкурентоспособность (рис.1).

Системный подход к управлению качеством предоставления услуг субъектами туристического предпринимательства в сельской местности должен начинаться с формирования параметра «выход» (услуги), который в свою очередь, должен обеспечивать их конкурентоспособность.

На следующем этапе по результатам обследования системы и параметров внешнего среды целесообразно определить параметры «вход».

Обратная связь является коммуникационным каналом, который позволяет «входу» системы, системе в целом реагировать на изменения, которые предопределяются факторами внутреннего и внешнего среды, и вносить соответствующие коррективы в параметры функционирования.

Для оценки качества предоставления услуг субъектами туристического предпринимательства в сельской местности необходимо их разделение на материальные и нематериальные.

Нематериальный элемент услуг - это атмосфера, привлекательность окружения, эстетика, комфорт. Также необходимо включить в этот перечень теплоту обслуживания, дружелюбие, покой и высокую культуру межличностного общения.

К материальному элементу относится жилищный фонд, товарно-материальные ресурсы и технология предоставления услуг. Физические характеристики создают контактную зону, в которой в процессе обслуживания взаимодействуют тот, кто предоставляет, и тот, кто потребляет услуги.

В табл.1 предоставленные характеристики некоторых оценочных элементов услуг, которые предоставляют субъекты туристического предпринимательства в сельской местности.

Методологическую основу исследований относительно качества предоставления туристических услуг субъектами предпринимательства в сельской местности составляют общенаучные, аналитико-прогностические методы, приемы, заимствованные из разных областей знаний, а также методы маркетингового анализа. 
Таблица 1 Характеристика некоторых оценочных элементов услуг, которые предоставляют субъекты туристического предпринимательства в сельской местности

\begin{tabular}{|c|c|c|}
\hline $\begin{array}{l}\text { № } \\
\Pi / \Pi\end{array}$ & $\begin{array}{l}\text { Оценочные элементы } \\
\text { услуг }\end{array}$ & Требования \\
\hline \multirow{3}{*}{1.} & \multirow{3}{*}{$\begin{array}{l}\text { Туристическая } \\
\text { информация }\end{array}$} & $\begin{array}{l}\text { Информация о местных культурных и исторических } \\
\text { ценностях }\end{array}$ \\
\hline & & Информация об охране окружающей среды \\
\hline & & $\begin{array}{l}\text { Карта местности, на которой обозначены } \\
\text { объекты территории, имеющие культурные и } \\
\text { исторические ценности }\end{array}$ \\
\hline \multirow{2}{*}{2.} & \multirow{2}{*}{ Транспорт } & $\begin{array}{l}\text { Обеспечение транспортными услугами между } \\
\text { усадьбой и ближайшей остановкой общественного } \\
\text { транспорта }\end{array}$ \\
\hline & & $\begin{array}{l}\text { Возможность аренды экологических транспортных } \\
\text { средств }\end{array}$ \\
\hline 3. & $\begin{array}{l}\text { Поддержка народных } \\
\text { традиций }\end{array}$ & $\begin{array}{l}\text { Размещение и быт туристов организованы согласно } \\
\text { старинному укладу крестьянского жизни }\end{array}$ \\
\hline
\end{tabular}

Нами для оценки качества предоставления услуг субъектами предпринимательства в сельской местности были применены метод Дельфи, который является неформализованным методом системного анализа качества и построение петли качества.

На основе проведенных исследований относительно оценки качества предоставления туристических услуг субъектами предпринимательства в Закарпатской, Волынской, Полтавский, Харьковских областях и Автономной Республике Крым построен радар их конкурентоспособности (по элементу «качество») (рис.2).

Еще одним методом оценки качества предоставления гостиничных услуг является построение петли качества. Система качества функционирует вместе с теми видами деятельности, которые влияют на качество услуги и взаимодействуют друг с другом. Ее действие распространяется на все этапы от начального до конечного удовлетворения требований и потребностей потребителя (в ИСА серии 9000 — «петля качества») ${ }^{10}$.

\footnotetext{
${ }^{10}$ Т. І. Ткаченко,Управління якістю готельних послуг : монографія / Т. І. Ткаченко, С. В.
} Мельниченко, М. В. Новак. - К. : Київ. нац. торг.- екон. ун-т, 2006. - 234 с. 
Рис.2. Радар конкурентоспособности туристических услуг субъектов предпринимательства в сельской местности Украины (элемент «качество»)

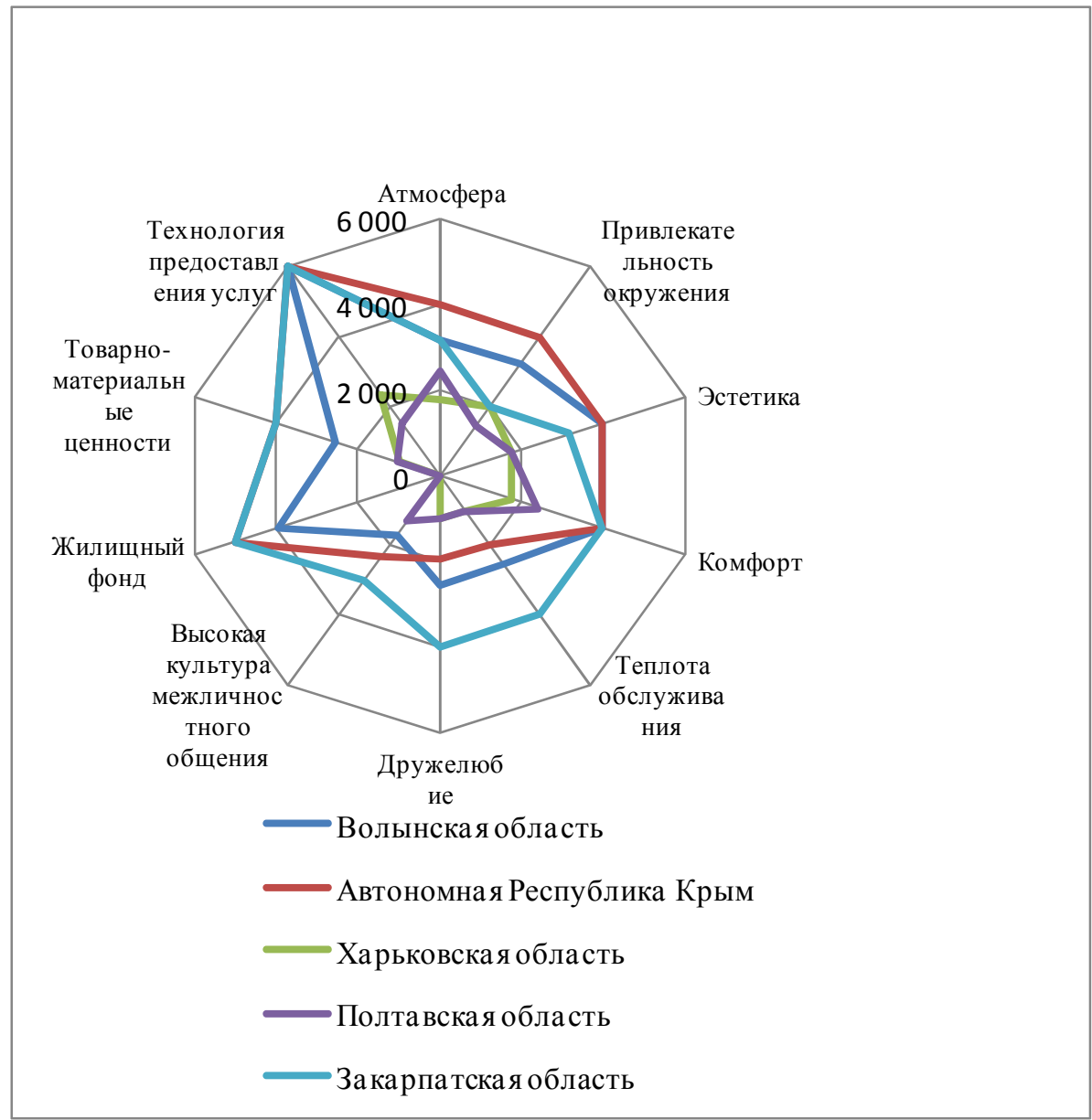

Основные этапы «петли качества» для субъектов туристического предпринимательства в сельской местности изображено на рис.3. 
РИС.3. «ПЕТЛЯ КАЧЕСТВА» ДЛЯ СУБЪЕКТОВ ТУРИСТИЧЕСКОГО ПРЕДПРИНИМАТЕЛЬСТВА В СЕЛЬСКОЙ МЕСТНОСТИ
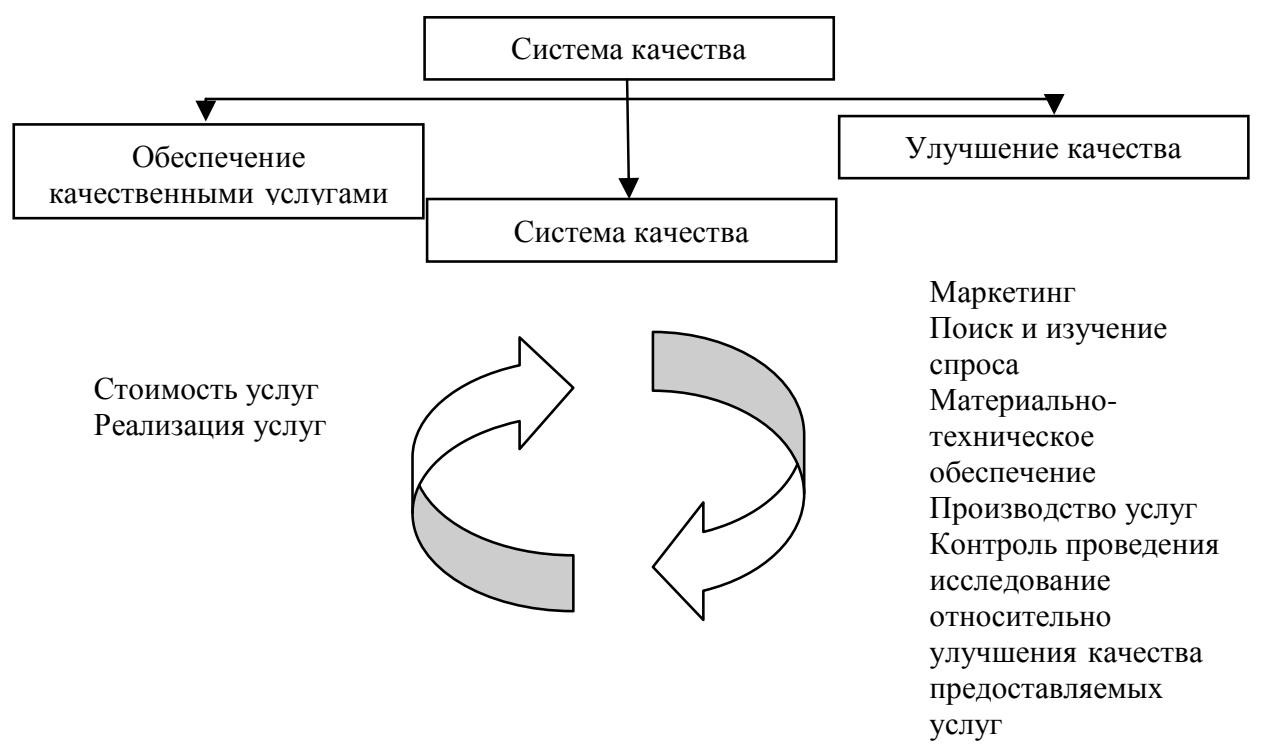

Требования к этим этапам приведены в табл. 2 .

Также, контроль и оценка качества туристических услуг должны осуществляться постоянно со стороны, как туристов, так и персонала субъектов туристического предпринимательства. При этом нужно применять разные методы исследования качества обслуживание. Анализ соответствия качества услуг требованиям потребителей нуждается в наличия определенных механизмов получения обратной связи. Источниками получения информации служат: результаты социологических исследований; средства массовой информации; Интернет; соответствующие подразделения местных органов власти; союзы и объединения. В процессе разработки туристического продукта субъект туристического предпринимательства должен учитывать пожелание потребителей, принимая во внимание полученную информацию. Для этого туристические предприятия используют специализированные программные продукты, которые позволяют учитывать как можно больше пожеланий клиента. В последнее время клиенты получили возможность самостоятельно подбирать субъекты туристического предпринимательства с определенным набором туристических услуг с помощью информационно-поисковых систем, которые содействует решению многих вопросов в сфере качества, в частности отстраняя из процесса этап непосредственного общения клиента с менеджерами, экономя время обеих сторон.

При выявлении ненадлежащего качества туристических услуг осуществляется корректирующее влияние. Возможность обмениваться информацией с помощью глобальной сети в режиме реального времени обеспечивает быстрое устранение выявленных несоответствий при предоставления туристических услуг всеми задействованными в этом процессе субъектами. 
Оценивая обслуживание, необходимо учитывать соответствие не только требованиям относительно качества туристических услуг, а и принципам управление качеством. Современные отечественные научные работники предлагают разные принципы, а именно: управление качеством должно осуществляться на всех уровнях и опираться на систему качества, поскольку оно является составляющей общего механизма управления субъектом туристического предпринимательства; должны базироваться на нормативных документах Украины и международных регламентах и стандартах; процессы должны распространяться на весь жизненный цикл продукции и услуг от проектирования до реализации; обеспечивать системный подход и комплексность, научный подход к решению проблем управления качеством; формирование четких показателей оценки уровня качества услуг; учет приоритета человеческого фактора; управление качеством базируется на требованиях Национальной системы стандартизации и нуждается в постоянном усовершенствовании ${ }^{11}$.

Таблица 2 Основные этапы «Петли качества»

\begin{tabular}{|c|c|c|}
\hline $\begin{array}{l}\text { № } \\
\Pi / \Pi\end{array}$ & $\begin{array}{c}\text { Этапы «петли } \\
\text { качества» }\end{array}$ & Сущность требований к качеству услуг \\
\hline 1 & 2 & 3 \\
\hline 1 & Маркетинг & $\begin{array}{l}\text { Функция маркетинга должны играть руководящую роль } \\
\text { в определении требований к качеству предоставляемых услуг: } \\
\text { - определять потребность в услугах; } \\
\text { - давать точное определение рыночного спроса в услугах; } \\
\text { - давать четкое определение требований потребителей на } \\
\text { основе постоянного анализа договоров, контрактов или } \\
\text { потребностей рынка; } \\
\text { - четко информировать в } \quad \text { пределах } \\
\text { предпринимательства обобекта всех требованиях, которые } \\
\text { выдвигают потребители туристических услуг }\end{array}$ \\
\hline 2 & $\begin{array}{l}\text { Материально- } \\
\text { техническое } \\
\text { обеспечение }\end{array}$ & $\begin{array}{l}\text { - четкое установление требований к качеству услуг; } \\
\text { - определение процедур, методов и норм работы с } \\
\text { потребителями услуг; } \\
\text { - входной контроль; } \\
\text { - процедурные положения по решению спорных вопросов } \\
\text { относительно качества услуг; } \\
\text { - регистрация данных о качестве услуг и оценки потребителей }\end{array}$ \\
\hline 3 & $\begin{array}{c}\text { Предоставление } \\
\text { услуг и } \\
\text { контроль } \\
\text { качества }\end{array}$ & $\begin{array}{l}\text { - технологический процесс и состояние всех элементов } \\
\text { производства услуг обеспечивают предоставление услуг } \\
\text { согласно требованиям стандартов ИСА серии 9000; } \\
\text { - все элементы производства услуг должны быть управляемы } \\
\text { (координация и контроль); } \\
\text { - результаты оценки качества услуг необходимо использовать } \\
\text { при корректировке предоставления } \\
\text { стимулирования отдельных работников за качество } \\
\text { предоставляемых ими услуг }\end{array}$ \\
\hline
\end{tabular}

${ }^{11}$ Т. Ткаченко, І. Управління якістю готельних послуг : монографія / Т. І. Ткаченко, С. В. Мельниченко, М. В. Новак. - К. : Київ. нац. торг.- екон. ун-т, 2006. - 234 с. 
Принципы управления качеством с учетом отраслевой специфики туристической деятельности в сельской местности нужно дополнить следующими:

- обеспечение качества туристических услуг на всех уровнях управления во всех задействованных в этом процессе субъектах туристической деятельности;

- налаживание таких взаимодействий, при которых каждый сотрудник способен решать проблемы качества туристических услуг на своем рабочем месте;

- управление качеством туристических услуг на основе собранной информации относительно изменений в нуждах клиентов, стратегии и тактики конкурентов, а также в своих ресурсах, технологических возможностях и мощностях;

- соответствие качества цене туристической услуги;

- обеспечение прибыльности за счет улучшения качества туристических услуг;

- применение и внедрение современных информационных технологий как ключевого фактора обеспечения качества туристических услуг.

\section{4. ВЫВОДЫ}

На сегодня одним из самых важных направлений в деятельности субъектов туристического предпринимательства в сельской местности является создание эффективной системы управления качеством, которая позволит осуществлять предоставления конкурентоспособных услуг. Управление качеством обслуживания нуждается в не только установлении процессов, необходимых для эффективного обслуживания потребителей, определении их последовательности и взаимосвязи, но и для обоснования критериев их оценки, ресурсного обеспечения реализации процессов, их мониторинга, систематического анализа процессов, выполнения запланированных мероприятий по обеспечению результативности процессов, их постоянного улучшения.

\section{ЛИТЕРАТУРА}

[1] АГАФОНОВА Л.Г. ТУРИЗМ, ГОТЕЛЬНИЙ Та РЕСТОРАННИЙ БІЗНЕС/ Л.Г. АГАФОНОВА, О.С. АГАФОНОВА. - К. : Знання України, 2002.

[2] Алябышева Т. М. Теоретические и методические аспекты оценки конкурентных преимуществ региона / Т. М. Алябышева // Культура народов Причерноморья. - 2007. - № 102

[3] Глівенко С.В. Економічне прогнозування [Текст] : навч. посібник / С. В. Глівенко, М. О. Соколов, О. М. Теліженко. - 3-є вид., доп. - Суми : Університетська книга, 2004..

[4] Малевський Е. 3. Стратегія формування та досягнення конкурентних переваг промисловим підприємством / Е. 3. Малевський // Культура народов Причерноморья. - 2007. - №103.

[5] Половинка Ю. С. Концепція управління якістю / Ю. С. Половинка, І. С. Грозний // Інтеграційні процеси і соціально-економічний розвиток : міжн. науково-практ. конфер., 25-26 квітня, 2007 р. : тези конф. - Сімферополь : Таврія, 2007.

[6] Роглєв Х.Й. Основи готельного менеджменту [Текст] : підруч. для студ. вищ. навч. закл. / Роглєв Х.Й. ; Київськ. ун-т туризму, екон. і права. - К. : Кондор, 2009. 
[7] Ткаченко Т. І. Управління якістю готельних послуг : монографія / T. I. Ткаченко, С. В. Мельниченко, М. В. Новак. - К. : Київ. нац. торг.- екон. ун-т, 2006.

[8] Унтила Е. Н. Экологическая составляющая конкурентоспособности фирмы / Е. Н. Унтила // Культура народов Причерноморья. - 2001. - №21.

[9] Фатхутдинов Р. А. Конкурентоспособность организации в условиях кризиса: экономика, маркетинг, менеджмент / Р. А. Фатхутдинов. - М. : Маркетинг, 2002.

[10] Mazurkiewicz L. Planowanie marketingowe w przedsiębiorstwie turystycznym. Warszawa, 2002.

\section{ESTIMATION OF THE COMPETITIVENESS OF TOURIST SERVICES BUSINESSES IN RURAL AREAS (THE ELEMENT OF "QUALITY")}

The article deals with the study of the existing approaches to the essence of competitiveness of enterprise, concept of management of quality of tourist services in rural tourism, proposed author's position in creation system of management competitiveness of tourism businesses in rural areas on the element of "quality of service ". The authors have proved that the essence of quality management of tourist services in rural tourism is the formation of management decisions and implement these decisions, provided administrative actions regarding the business processes that affect the quality of services, namely, documented instructions on technology services and maintenance, regulation and process management of tourist services, the criteria of works presented in the form of standards, use of new information technologies in the production, sale and promotion of tourism services on the market.

To assess the quality of services by businesses in rural areas the Delphi method have been applied, which is a formalized method of system analysis of quality and build quality hinges. Also, the article presents the results of studies on the evaluation of the quality of tourist services business entities in different regions of Ukraine and built the radar of their competitiveness (based on studies on the evaluation of the quality of tourist services business entities in the Transcarpathian, Volyn, Poltava, Kharkiv region and the Autonomous Republic). Also, complemented by the principles of quality management based on industry-specific tourism activities in rural areas, among which should be allocated to ensure the quality of tourist services at all levels of governance in all involved in the process of tourist activities, the establishment of such interactions in which each employee is able to solve quality problems travel services in the workplace, quality management of tourist services on the basis of the information collected on changes in customer needs, strategies and tactics of the competitors, as well as their resources, technological capabilities and capacities.

Keywords: rural tourism, enterprise competitiveness, quality of tourism services , quality loop, quality management principles of tourist services.

DOI:10.7862/rz.2014.hss.32

Przesłano do redakcji: marzec 2014

Przyjęto do druku: lipiec 2014 